\title{
Design of Learning Evaluation Model for Distance Education
}

\author{
Gang Liu* \\ College of Continuing Education, Nanjing Forestry University, Nanjing 210037 \\ *Corresponding author. Email: gangliu@njfu.edu.cn
}

\begin{abstract}
It is one of the core tasks of distance education teaching reform to evaluate students' learning comprehensively. It is an effective measure to ensure the healthy development of distance education. In this paper, based on the online learning behavior of students, a learning evaluation model of distance education is designed. The learning evaluation model comprehensively evaluates the learning effect of students from two aspects: formative evaluation and summative evaluation, which provides a new reference for learning evaluation of distance education.
\end{abstract}

Keywords: Distance education, learning evaluation model, formative evaluation, summative evaluation

\section{INTRODUCTION}

Distance education refers to the teaching mode using television and the internet and other communication media. It breaks through the boundaries of time and space. It is a new concept generated by the application of modern information technology in education and is a form of adult education. With the rapid development of distance education, more and more people are participating in distance education. Students can learn through a variety of channels, including television broadcasts, the internet, and face-to-face. Distance education has innovated the talent training model, allowing more people to learn knowledge and continuously improve themselves, making a positive contribution to the realization of popular education. Learning evaluation of distance education is an important way to stimulate students' learning and promote their self-improvement in the process of learning. Distance education has its own unique learning characteristics. Students can study independently at anytime and anywhere. Teachers and students are in different environments, and teaching and learning are separated. So it also puts forward a test of students' autonomous learning ability. Under the online learning environment, how to evaluate students' learning effect comprehensively is a hot research topic. With the application of information technology in the field of education, the learning evaluation of distance education has gradually shifted to intelligent and digital. However, there are some problems in the learning evaluation of distance education, such as lack of formative evaluation system and incomplete evaluation criteria. Therefore, it is very meaningful to build a learning evaluation model suitable for distance education.

\section{THE PRINCIPLE OF LEARNING EVALUATION}

\subsection{The Principle of Unity of Scientificity and Feasibility}

Scientificity means that learning evaluation should act according to the objective law of learning evaluation activities, take the scientific learning evaluation index system as the scale, take the evaluation information as the basis, and feasibility means that the evaluation index system and methods and technologies should be as simple and easy as possible.

\subsection{The Principle of Combining Constant Evaluation and Periodic Evaluation}

Periodic evaluation refers to the regular teaching evaluation, such as final evaluation and year-end evaluation. Constant evaluation refers to continuous teaching evaluation, such as daily and weekly teaching inspection and evaluation to ensure the realization of the function of teaching evaluation.

\subsection{The Principle of Combining Formative Evaluation and Summative Evaluation}

How to give formative evaluation objectively is a hot topic in future research. The development of the Internet provides technical support for the formative evaluation of distance education. The learning evaluation system automatically tracks, records, stores, and establishes students' learning 
process files through the network. The learning process file can better reflect the learning process and the final result of the students, so it can be used as one of the basis for direct evaluation of students' learning effects. Using the learning process file can not only collect the learning behavior of the student entity, but also judge the learning habits and interests of the students, and guide the students' personalized development.

\subsection{The Principle of Combining Students' Self-Evaluation and Mutual Evaluation}

The main body of learning evaluation in distance education should be students. On the one hand, many processes of learning evaluation depend on students' independent implementation, such as practice, test, etc. On the other hand, in collaborative learning, the interaction between teachers and students, students and students will play a role. The mutual evaluation between students is reflected in the mutual observation and test in the learning process [1].

\section{THE CONTENT OF LEARNING EVALUATION}

\subsection{Learning Attitude}

The learning attitude directly influences the students' learning result. Students with active learning attitudes believe that learning is a meaningful and happy thing, willing to pay emotions, time and energy, can actively overcome difficulties, and persist in completing tasks and goals of learning. The main contents that reflect students' learning attitudes are: the formulation of personal learning plans, the number of browsing related learning resources, the number of published learning experiences, online learning notes, and participation in discussion forums, etc.

\subsection{Self-Learning Ability}

Self-learning ability is the basic condition to ensure the learning effect of distance education. Under the condition of less external supervision, students' self-learning ability is particularly important. The evaluation of self-learning ability helps students to enhance their self-management awareness and better adapt to the distance education learning environment. The main contents that reflect students' active learning ability are: the number of online learning, the length of continuous online learning time, online homework times and grades, etc. The number of homework assignments and grades can be used to reflect how much students understand what they have learned. The design requirements for assignments include not only declarative knowledge, but also the question of developing students' advanced thinking skills [2].

\subsection{Interactive Learning Ability}

Distance learning resources include CD-ROMs, books and teachers provided by distance learning institutions. The ability to use learning resources is a direct reflection of students' learning. The students' understanding and digestion of learning content determines the final learning effect. Teachers are an important learning resource, and communication between students and teachers is an important aspect of using learning resources. The e-learning platform can record the number of times students ask questions from teachers and the solutions provided by teachers.

Information transmission in distance learning is two-way interactive. Students can interact with teachers and other students through computer network interactive media such as BBS, chat rooms, E-mail, video or audio conference systems on distance learning platforms. So, the evaluation of student interaction ability can be recorded by the number and mode of students using the online learning platform, such as the number and content of posts and replies, the number and content of online answering and questions, etc [3].

\section{PROBLEMS IN DISTANCE LEARNING EVALUATION IN CHINA}

\subsection{Lack of Formative Evaluation}

Learning evaluation needs to run through the entire process of student learning. According to the learning evaluation results, students can continuously adjust the learning progress under the intervention of their own or the teacher. Teachers can reasonably adjust the content and form of teaching to improve the learning effect of students. Therefore, the learning effect evaluation of distance education should at least include two aspects: summative evaluation and formative evaluation. At present, the method of learning evaluation in distance education in China still refers to the evaluation method of general higher education. Most of the evaluation subjects are teachers, and the evaluation content is limited to the cognitive test of general knowledge, lack of comprehensive professional ability of students, the evaluation method is mainly terminal examination, lack of process assessment, etc. Neglecting the importance of process evaluation will lead to the unsatisfactory effect of learning evaluation. Through learning evaluation, students can't realize their own problems in learning, and the role of learning evaluation is greatly weakened [4]. 


\subsection{Lack of Evaluation Indicators}

At present, the evaluation indicators of distance learning mainly refer to the traditional teaching evaluation methods, which are generally determined by the homework scores and final exam scores. This kind of learning evaluation is unique and one-way, and the evaluation information obtained is incomplete, and it is impossible to comprehensively evaluate the learning effect and learning ability of students. This method of learning evaluation does not conform to the evaluation law of distance learning. In the distance learning environment, the learning status and learning ability of students play an important role in the learning effect. The learning evaluation data and indicators should also be factors that accompany the learning process, such as learning attitude, self-learning ability, etc [5].

\section{DESIGN OF LEARNING EVALUATION MODEL}

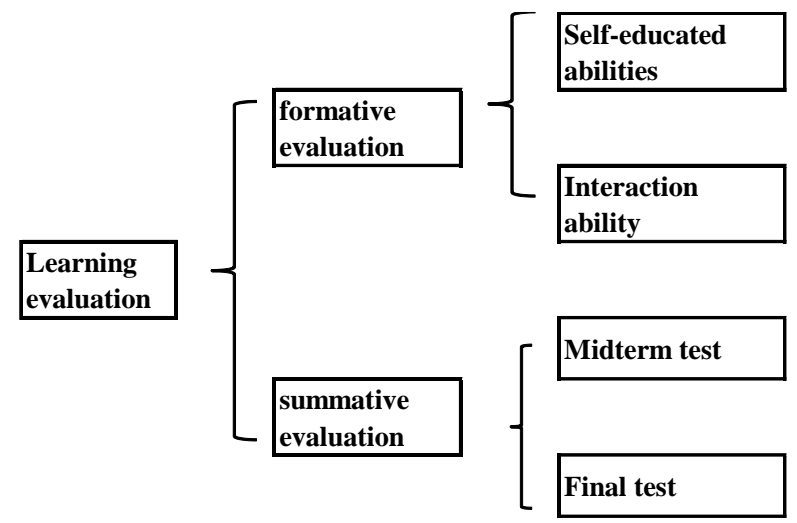

Figure 1 The model of learning evaluation system

The development of modern information technology provides a basis for collecting student learning behavior data. Learning evaluation platforms can record students' various learning behaviors. These behaviors reflect students' learning status and effects from different aspects, making learning evaluation more three-dimensional. In the construction of distance learning evaluation system, it is very important to choose the source of learning behavior data. However, it is not necessary to collect all the data, because if every learning behavior data is evaluated and judged as a feature, it will also cause unnecessary redundancy and computational complexity. Which data is selected from the many characteristic data to participate in the evaluation? Based on experience, combined with the characteristics of distance learning and the requirements of diversified evaluation, the following data sources for learning evaluation were finally selected, such as the number of online learning, the length of online learning, the homework times, the homework score, online posts and replies, online questions and answers, the mid-term test, and the final test.
Our learning evaluation model includes two aspects: formative evaluation and summative evaluation. The model is shown in Figure1. Formative evaluation consists of two aspects: self-learning ability and interaction ability. Summative evaluation is commonly staged test results, including mid-term tests and final results. The self-learning ability mainly refers to the number and time of learning, homework times and homework scores. Interaction ability is mainly reflected in the number and content of online posts and replies, online questions and answers. The formative evaluation structure is shown in Figure 2.

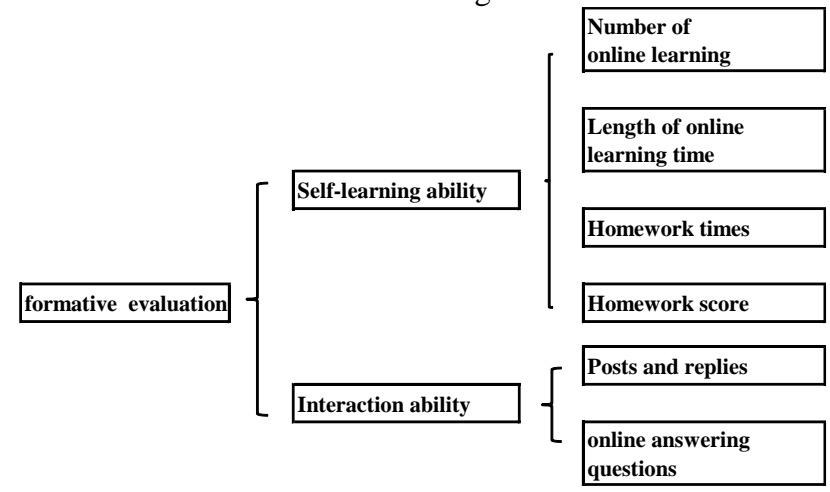

Figure 2 Composition of formative evaluation system

Table 1 Score setting of different evaluation indexes

\begin{tabular}{|c|c|c|c|}
\hline \multirow{8}{*}{$\begin{array}{l}\text { System } \\
\text { evaluation } \\
(100)\end{array}$} & \multirow{6}{*}{$\begin{array}{l}\text { formative } \\
\text { evaluation } \\
(50)\end{array}$} & $\begin{array}{l}\text { Number of } \\
\text { online learning }\end{array}$ & 5 \\
\hline & & $\begin{array}{l}\text { Length of online } \\
\text { learning time }\end{array}$ & 15 \\
\hline & & Homework times & 5 \\
\hline & & Homework score & 15 \\
\hline & & $\begin{array}{l}\text { online Posts and } \\
\text { replies }\end{array}$ & 5 \\
\hline & & $\begin{array}{l}\text { online answering and } \\
\text { questions }\end{array}$ & 5 \\
\hline & \multirow{2}{*}{$\begin{array}{l}\text { summative } \\
\text { evaluation } \\
(50)\end{array}$} & Midterm test & 25 \\
\hline & & Final test & 25 \\
\hline
\end{tabular}

In our model, the proportion of formative evaluation and summative evaluation is equal, each accounting for 50 points. Summative evaluation is based on test scores. The tests include theoretical tests and practical tests. The practical test uses a grade system. The theoretical test uses a score system. The proportion of theoretical and practical tests is allocated according to the curriculum outline requirements. If the mid-term exam and the final exam are taken, the mid-term exam and the final exam each take 25 points. If there is only the final exam, the final exam is 50 points. In the formative evaluation, the number of times of learning, homework times, online posting and replying, and online questions and answers each accounted for 5 points. At the beginning of the term, the teacher sets the number of learning times according to the class hours of the course. Open evaluation mode is adopted for the number of posts, replies and online answers. The minimum number is set for each semester. The final score is evaluated by teachers according to the quality and quantity of online answers and 
questions, posts and replies. The length of online learning and homework scores each account for 15 points. Score setting of different evaluation indexes is shown in table1.The minimum evaluation cycle of formative assessment is one week. At the beginning of the semester, the teacher will make the number of times to learn the length of learning time and the number of assignments according to the teaching plan.

Formative evaluation data is recorded by the system from time to time. At each stage (usually one month), the system synthesizes the evaluation value of each student. The evaluation results and relevant data are fed back to students and teachers in the form of reports. Students compare their learning status and scores, find out their own shortcomings, and adjust their learning schedule and learning attitude. Teachers can also give appropriate teaching intervention to those who need help.

\section{DISCUSSION}

Learning evaluation model can help students find their own problems in learning, adjust learning progress in time, optimize learning methods, and improve learning quality. The feedback of learning evaluation results is conducive to the self-improvement of students and provides guidance for the improvement of students' self-learning ability.

But our model still has many shortcomings, such as:

First, summative evaluation still occupies an important part. According to the principle that the result is the product of the process, as long as the formative evaluation setting is sufficiently fine, the proportion of the summative evaluation can become less and less.

Second, there are too few data indicators in the formative evaluation, and lack of subjective factors, such as learning attitude and learning emotions. The emotions that people pay in the learning process cannot be ignored.

Third, personal evaluations were not included in the final evaluation indicators. According to the principle that individual learning results are determined by individual learning behaviors, everyone can make a reliable evaluation of their own learning results. Making a reliable judgement of one's own status is also a content that students should learn.

Finally, mutual evaluations between students were not included in the final evaluation index. In traditional teaching, students study together every day, and the data of mutual evaluation is basically reliable. In distance education, students are separated. It is difficult to judge whether the data of student mutual evaluation is reliable. In the future research, we will improve and upgrade the model. We will explore the indicators for formative assessment through multiple channels, such as learning attitude, learning motivation, learning emotion and other emotional factors, and refine the scores of formative assessment indicators.

\section{CONCLUSION}

In this paper, a distance education learning evaluation model was constructed. The model includes formative evaluation and summative evaluation. In this model, the proportion of the two parts is the same. Summative evaluation uses mid-term and final examinations to form results, and the proportion of the mid-term and final examination scores is equal. In order to increase the reliability of formative assessment, the model forms formative assessment from two aspects: self-study ability and interaction ability. Combined with the characteristics of distance education, six main elements are selected as the main elements of formative evaluation, including learning times, homework times, learning time, homework scores, posting times and reply times, questions and answers.

\section{REFERENCES}

[1] Zhang Qianwei, sang Xinmin. Exploring a new learning evaluation model in the network environment [J]. China distance education, 2002 (02): 53-55 + 80

[2] Cao Mei, Li Yi. Significance and principles of online learning evaluation [J]. Education science, 2002 (05): $50-52$

[3] Wu Lan, ZhongZhixian. Performance evaluation: an effective learning evaluation method of Distance Education [J]. Journal of distance education, 2007 (04): $14-17$

[4] Wu Gang, Zhu Xiaoqing. Analysis on the developmental evaluation system of learning ability of Open University Students [J]. Modern distance education, 2005 (06): 11-14

[5] Wang Lihong, Xu Wei, Wang Zuli. Study on learning evaluation strategies based on learners' behavior in Distance Education [J]. Journal of Hubei open vocational college, 2019,32 (16): 28-29 